\title{
Incorporating Pronunciation in Day-to-Day Activities
}

\author{
Linh Dam Mai Ly \\ Hoang Le Kha High School for the Gifted Affiliation, Tay Ninh Province
}

\begin{abstract}
Teaching pronunciation by itself is hard to do without context; it should be related to specific lessons. Moreover, pronunciation is a necessary component for students in everyday and academic tasks. This presentation offers warm-up activities that EFL instructors can use on a daily basis to help students develop
\end{abstract} pronunciation skills.

\section{Session Description}

Studies have shown that some teachers in ESL contexts find teaching pronunciation problematic (McDonald, 2002). The EFL context offers more difficulties. Reasons may vary from the limited time devoted to pronunciation in the curricula to the lack of assessment frameworks (McDonald, 2002). In Vietnamese high schools, pronunciation work is narrowly focused, covering one sixth of a page, and appears only twice in every ten pages of each unit from the textbook used in $10^{\text {th }}$ grade. Assessing pronunciation is in the form of multiple choice written questions. Moreover, the absence of pronunciation materials suitable to current English textbooks can also be considered an obstacle for high school teachers. The consequence that follows is some teachers give cursory lessons and most high school students are not able to get themselves understood sufficiently. This presentation focuses on how to make pronunciation a short, fun, daily activity by integrating pronunciation into almost any lesson. The presenter demonstrates how EFL teachers can design their own pronunciation activities related to each lesson to introduce the new lesson. Examples of lessons will be provided under the theme “inventions” for each of the skills: Reading, Writing, Listening, and Speaking. Suggestions of additional exercises are another part of the presentation. After this presentation, the audience members will leave with at least four detailed activities to teach pronunciation at the beginning of lessons and, more importantly, they will be motivated to try out this idea in their own classroom, regardless of what level they 
teach or textbook they use. This presentation will be useful to EFL professionals who are in K-12 education and are interested in teaching pronunciation, using authentic materials, or simply interested in having fun ways to introduce lessons.

\section{References}

McDonald, S. (2002). Pronunciation - Views and practices of reluctant teachers. Prospect, 17(3), 3-18. 